\title{
Por entre Caixas de Memória: A constituição do acervo do Núcleo de Extensão e Pesquisa em Educação, Memória e Cultura-NEPEC
}

\author{
Por entre cajas de la memoria: La constitución de la colección del Núcleo \\ de Extensão e Pesquisa em Educação, Memória e Cultura-NEPEC
}

\section{Between Memory Boxes: The constitution of the collection of the Núcleo de Extensão e Pesquisa em Educação, Memória e Cultura-NEPEC}

\author{
Angelita Soares Ribeiro ${ }^{1}$ \\ Fabíola Mattos Perreira ${ }^{2}$ \\ Leandro Rodrigues da Silva ${ }^{3}$ \\ Patricia Nunes 4
}

\begin{abstract}
Resumo
O texto que aqui apresentamos, coloca-se como uma tentativa de contar acerca da constituição do Núcleo de Extensão e Pesquisa em Educação, Memória e Cultura (NEPEC), a partir do processo de salvaguarda do antigo "arquivo morto" do Campus Pelotas Visconde da Graça (CaVG), do Instituto Federal de Educação, Ciência e Tecnologia Sul-Rio-grandense (IFSul). Para isso elegemos uma imagem: as "caixas de memória" que, em abertura revelam seu material, para logo fecharem-se, anunciando e acenando como "alguma coisa", um "mesmo assim", que em memória sobrevive e tensiona os sentidos comuns e já estabelecidos acerca da constituição de um acervo.
\end{abstract}

Palavras-Chave: Memória; Acervos; História.

\section{Resumen}

El texto que aquí se presenta se coloca como un intento de contar sobre la constitución del Núcleo de Extensão e Pesquisa em Educação, Memória e Cultura (NEPEC) desde el proceso de salvaguarda de lo antiguo " archivo muerto" de lo Campus Pelotas Visconde da Graça (CaVG) del Instituto Federal de Educação, Ciência e

\footnotetext{
${ }^{1}$ Mestre em Ciências Sociais/Doutoranda em Educação; Universidade Federal de Pelotas (UFPel)/ Assistente Social no Campus Pelotas Visconde da Graça (CaVG) do Instituto Federal de Educação, Ciência e Tecnologia Sul-Rio-grandense (IFSul); Pelotas, Rio Grande do Sul, Brasil. E-mail: sr-angelita@ hotmail.com.

${ }^{2}$ Mestre em Ciências Sociais/Doutoranda em Ciências Sociais; Pontifícia Universidade Católica do Rio Grande do Sul (PUCRS)/ Docente no Campus Pelotas Visconde da Graça (CaVG) do Instituto Federal de Educação, Ciência e Tecnologia Sul-Rio-grandense (IFSul); Pelotas, Rio Grande do Sul, Brasil. E-mail: faby_mattos@yahoo.com.br.

${ }^{3}$ Tecnólogo em Gestão Ambiental. Campus Pelotas Visconde da Graça (CaVG) do Instituto Federal de Educação, Ciência e Tecnologia Sul-Rio-grandense (IFSul); Pelotas, Rio Grande do Sul, Brasil. E-mail: le.leandro.rds@gmail.com.

${ }^{4}$ Tecnóloga em Gestão Ambiental. Campus Pelotas Visconde da Graça (CaVG) do Instituto Federal de Educação, Ciência e Tecnologia Sul-Rio-grandense (IFSul); Pelotas, Rio Grande do Sul, Brasil. E-mail: patricia_spaik@hotmail.com.
} 
Tecnologia Sul-Rio-grandense (IFSul). Para ello se ha elegido una imagen: las "cajas de memoria", que, en la apertura de mostrar sus talentos, para luego ser-anunciando cerrada, agita como "algo", un "todavía", que sobrevive en la memória, y aprieta los sentidos común y ya establecido en el establecimiento de una colección.

Palabras claves: Memoria; Colecciones; Historia

\begin{abstract}
The text presented here is an attempt to tell about the constitution of the Núcleo de Extensão e Pesquisa em Educação, Memória e Cultura (NEPEC) from the process of safeguarding the former "dead file" of the Campus Pelotas Visconde da Graça (CaVG) of the Instituto Federal de Educação, Ciência e Tecnologia Sul-Rio-grandense (IFSul). For this we choose an image: the "memory boxes", which in openness reveal their material, then close, announcing and beckoning as "something", a "like that", that in memory survives and stresses the senses Established and established provisions on the constitution of a collection.
\end{abstract}

Keywords: Memory; Collections; History.

\title{
1. Introdução
}

O texto que aqui apresentamos, coloca-se como uma tentativa de contar acerca da constituição do Núcleo de Extensão e Pesquisa em Educação, Memória e Cultura (NEPEC), a partir do processo de salvaguarda, iniciado em 2014, do outrora "arquivo morto" do Campus Pelotas Visconde da Graça (CaVG), do Instituto Federal de Educação, Ciência e Tecnologia Sul-Rio-grandense (IFSul). Paras isso elegemos uma imagem: as "caixas de memória".

O grupo tem seu início diante a uma necessidade pressentida por alguns servidores, alunos e colaboradores externos, em buscar mais profundamente a história do CaVG- fundado em 1923 como Patronato Agrícola Visconde da Graça - a partir dos sujeitos que a vivenciaram, em especial, os alunos que desde a década de 1920 são conhecidos como internos, por residirem na moradia estudantil do campus. Buscamos, desde o início da constituição do grupo, tensionar sobre as vozes ainda silenciadas e os rostos ainda anônimos. Diante disso, logo percebemos que tais buscas não poderiam se dar longe de um processo de rememoração dos antigos materiais da instituição.

Após um processo denso que culminou na obtenção da salvaguarda provisória do outrora "arquivo morto", hoje Acervo do NEPEC, começamos em outras e ainda mais densas etapas. O trato diário com os materiais colocaram em evidência uma ação em particular: "abrir, olhar, higienizar identificar, e fechar caixas". Inicialmente, as caixas eram uma forma de acondicionamento, resultado e desfecho de um longo processo de trabalho de preservação dos materiais. No entanto, logo tornaram-se pilhas e mais pilhas que iam crescendo e acumulandose par a par, no ritmo de nosso trabalho, das nossas surpresas, encantamentos e das múltiplas indagações que os materiais iam nos colocando. Em sentimento de quase exaustão e êxtase, seguíamos abrindo e fechando, sem saber ainda com o que estávamos nos deparando... Sabendo que aquele fechamento era apenas temporário, mas necessário, apenas seguíamos, e ainda 
seguimos, observando o modo como as caixas espalham-se por todos os ambientes, preenchendo estantes, ocupando salas do chão ao teto, transbordantes de diferentes dimensões do mundo institucional, emaranhadas com vidas que deixaram pequenas marcas nos documentos, múltiplas vozes ainda não suficientemente ouvidas, rostos ainda anônimos.

Neste ritmo ainda em descompasso e sem direção certa para o próximo passo, construímos o movimento de escrita deste texto, com um bailar frenético pelas caixas que nos cercam, como já mencionamos, procurando construir e refletir sobre a constituição do acervo e do próprio NEPEC, tendo como fio condutor estas caixas em seus insistentes movimentos de abertura e fechamento. São assim "caixas de memória" que, em abertura, revelam seu material e logo fecham-se, conduzindo-nos a uma busca infinda dos significados que em sobrevivência anunciam e acenam, como alguma coisa, um mesmo assim que nos ultrapassa. "Como nomear isso? Como abordá-lo? Essa alguma coisa, esse mesmo assim estão no lugar de uma abertura e de uma cisão: a visão ali se rasga entre ver e olhar, a imagem ali se rasga entre representar e se apresentar." (DIDI-HUBERMAN, 2013, p. 205).

Didi-Huberman (2013) vai assim nos dando pistas da forma como as representações clássicas se rasgam quando buscamos profundamente uma imagem. Trata-se de compreender a forma como a abertura dos sentidos e dos significados nas imagens se fará sempre em uma cisão, revelando apenas fragmentos, metades. Por isso a apresentação é necessária, para dar conta daquilo que a representação já não alcança, de um mesmo assim, alguma coisa que permanece, em sobrevivência. Trata-se de pensar em uma dimensão estética que, para se abrir ao existente, necessita que fechemos os olhos. "Essas estéticas são sempre singulares, se desnudam no não-saber, e nunca hesitam em chamar de visão o que ninguém desperto vê." (DIDI-HUBERMAN, 2013, p. 206).

No livro "La imagen mariposa", Didi-Huberman (2007, p. 09) trata das imagens como "um bater de asas", como uma porta que se abre para logo fechar-se. Neste movimento o pensamento corre o risco de equivocar-se. O primeiro equívoco refere-se à crença em poder apropriar-se daquilo que acaba de aparecer, esquecendo que o que vem logo em seguida à aparição é desaparecimento. “[...] una cosa, una mariposa, no aparece sino para desaparecer al instante.” (DIDI-HUBERMAN, 2007, p. 09). Entretanto, o segundo equívoco do pensamento é crer que o desaparecido já não existe. “[...] lo que ya no está permanece, resiste, persiste tanto en el tiempo como en nuestra imaginación, que lo rememora". (DIDI-HUBERMAN, 2007, p. 09).

Pelas pistas que Didi-Huberman anuncia ao falar das imagens, quase que sufocados pela poeira que a abertura de cada caixa levanta em redemoinho, seguimos, com olhos por vezes 
fechados, com passos desajeitados em corpos tateantes... Assumindo que a busca pelos significados e memórias que essas caixas abrigam, em abertura e fechamento, excede-nos em possibilidade de representação.

Neste percurso, pela escrita, vamos refletindo sobre experiências para onde as caixas foram nos levando. Trata-se de um exercício coletivo vivenciado entre os integrantes do NEPEC e alguns pares, em que partimos de um filme "Uma vida iluminada" e de um acontecimento prenhe de significados - instante em que recebemos de "presente" uma caixa de memória de um ex-aluno. Ainda trazemos, ao texto, fragmentos de uma oficina de escrita que pretendeu abrir caixas e escrever coletivamente sobre o que nos saltava de lá. A escrita coletiva que tal oficina disparou, foi um misto de engajamento e afeto pelos materiais e o processo de rememoração que eles nos exigem, aspectos fundamentais no processo de pesquisa e constituição do acervo.

\section{Entre caixas, em direção a uma busca profunda}

Buscando pelos lugares onde poderíamos encontrar a palavra e a imagem que possibilitasse a história que desejávamos contar em processo de rememoração, começamos por um filme: "Uma vida iluminada". O drama de 2005, escrito e dirigido por Liev Schreiber, conta uma busca empenhada por Jonathan, um colecionador da memória de sua família, que intrigado com a ausência de lembranças materiais de seu avô recentemente falecido, empenha-se numa busca profunda, guiado apenas por um objeto recebido de sua avó: um pequeno pingente. Sua busca o leva até a Ucrânia, país de origem do seu avô, e lá guiado por Alexander Perchov, seu avô e o cachorro deles, ultrapassa as expectativas que imaginava atingir quando no início de sua viagem. O mergulho profundo das memórias familiares o aproxima do universo de dois judeus (seu próprio avô e o avô de seu guia) no contexto da II Guerra Mundial e aí se depara com o poder de vida e morte que a memória detém.

Ao conhecer a única habitante da cidade de Trachimbrod, Jonathan percebe e nos expôs a difícil e profunda experiência dos seres humanos com os objetos. A personagem encontrada, mantinha, em caixas de diferentes tamanhos, objetos que foram por ela retirados dos corpos mortos pelo regime nazista. A sua persistência de guardar objetos, cartas e pertences traz à tona a força dos objetos e documentos em se manterem prenhes de histórias, que podem um dia, mesmo soterrados, voltarem a viver. Quase inaudíveis não deixaram de sussurrar, e seu ápice o encontro de Jonathan, seus guias e a mulher, também colecionadora - produziu o despertar de muitas histórias de vida, principalmente, a do avô de Jonathan e de seu guia ucraniano (o avô de Alexander Perchov). 
Se os objetos e documentos contam histórias, ensina-nos o filme, eles nos mobilizam, inquietam-nos, desacomodam e nos conduzem a buscas e esquecimentos profundos. Acessar a memória a partir dos objetos, dos documentos, das imagens, dos restos é situar:

[...] objetos como importantes protagonistas no processo de revolvimento das camadas da memória e da construção das trajetórias sociais das personagens. Os objetos remetem, ao mesmo tempo, a uma trajetória singular - descrita pelo autor do livro e remontada pelo diretor do filme - e também a uma história coletiva, que diz respeito ao Holocausto e às inúmeras mudanças de rotas sociais realizadas durante este período (RIBEIRO, 2010, p.02).

No NEPEC, a busca profunda foi ocorrendo aos poucos. O empenho em abrir caixas e observar longamente os papéis que registravam as vozes e as impressões sobre os alunos e o modo como foram construídos, tem sido consequência de visões primeiras e revisões permanentes sobre os documentos que se avolumam no acervo. As vozes vão aos poucos, em gritaria, saindo das caixas, os rostos revelam-se como não mais anônimos. A sensação primeira de impotência no olhar, diante ao grande número de imagens acervadas, tem começado a transformar-se em um encontro profundo com os sujeitos registrados no suporte fotográfico. Os olhares que nos encaram em imagem congelada e eterna, começam a nos dizer algo e, por isso, não cabem mais nas caixas... Desejam vida, desejam contar daquilo que ainda não foi dito e redimido.

De modo geral os objetos, os documentos, as fotografias, os rolos de filme, etc. nos chegam em caixas. São variadas, com diferentes cores, tamanhos, formatos e texturas. A maioria delas nos foi "herdada" do antigo arquivo em deterioração, mas algumas outras começam a chegar como um presente, carregando dentro de si algo importante que é trazido a um amigo que saberá o que fazer com as coisas que ali se encontram guardadas. Ao serem abertas e colocadas de lado suas tampas, suas histórias são concedidas àqueles que as escutam e passam novamente a ecoar dentre as memórias tantas que transformaram o arquivo-morto em acervo histórico.

Recentemente um ex-aluno, hoje um professor do CaVG que vem dedicando-se há muito à preservação da história da escola, sendo também membro do NEPEC, chamou o restante da equipe do grupo, para uma pequena reunião. O referido professor está lançando seu segundo livro sobre a história do CaVG e o tema da reunião era este.

Entretanto, desde nossa chegada, quando ainda nem sabíamos o tema da reunião, o professor nos esperava com uma caixa de sapatos sobre a mesa. Antes de iniciar a reunião propriamente dita, ele, abrindo a caixa, que já nos produzia curiosidade, nos disse que "aquilo 
era para nós". A primeira coisa que vimos foram os slides... Mesmo porque foi a eles que o professor deu ênfase, tendo em vista nossas pesquisas com imagens. Ao começarmos a olhar os slides, ele percebeu que alguns deles não deveriam ser doados ao acervo, começando então a separá-los com nossa ajuda. Tratava-se de slides que ele usava na apresentação de seu trabalho de especialização e que ele gostaria de guardar com ele.

Depois de retirar os slides citados, ele nos disse que o restante era da escola... Que deveriam ficar no acervo do NEPEC. Além dos slides, estavam na caixa dois carimbos, de quando o professor foi diretor do $\mathrm{CaVG}$, um apontador verde com um ímã unido a ele e uma pequena etiqueta: "Mabram Troféus".

A caixa ficou o restante da reunião sobre a mesa, na nossa frente; Durante as duas horas em que estivemos frente à caixa, nós a tocávamos, tentando fazer com que as abas laterais da tampa retornassem ao lugar de origem, ainda que estivessem rasgadas. Fomos apenas perceber realmente "a caixa" enquanto tal, um pouco mais tarde. Olhando com mais atenção, era uma caixa já meio velha, amarela, estampava “Azaléia Beach”. Em registro já gasto, em caneta preta, dizia o nome do professor. Ainda mais apagado, quase imperceptível: "Objetos". Na parte superior esquerda, um número: “28”. Um dia aquela caixa tinha sido suporte de um sapato feminino tamanho "34", cor pérola.

A caixa começava a querer falar... Mas, que memórias ela continha? Qual o percurso que a levou de uma caixa que guardava o "chinelo perolado tamanho 34" a ser um lugar de guarda de "objetos do professor, $\mathrm{n}^{\circ} 28$ "? De quem era o chinelo? Porque caixa " 28 "? Onde estavam as outras? Da caixa " 1 ” à caixa "27”? E, mais do que tudo: O que significava a entrega daquela caixa para o NEPEC? Naquele momento lembramos também da ocasião em que um ex-aluno, já na faixa de seus 60 ou 65 anos, entregou-nos um envelope com fotos suas, quando aluno do CaVG. Disse-nos que eram cópias que ele tinha feito para que guardássemos no acervo.

Se voltarmos mais diretamente ao filme, é interessante mencionar que ele não fala apenas na necessidade do lembrar, mas também do esquecer. Enquanto o protagonista buscava tecer o fio da vida de seu avô, sem saber, traçava o fio da morte de um de seus guias, o mais velho, que há muito, em tentativa desesperada de sobrevivência, tentava esquecer ser ele outrora um judeu. Deparar-se com tantas caixas, que lhe gritavam o que tinha dedicado a vida a esquecer, significou sua morte, e, talvez, libertação. A memória se faz entre um tênue tecer e destecer, entre lembrança e esquecimento, entre vida e morte.

O esquecimento se coloca no processo de rememoração, não apenas como um lapso, mas como algo que delimita, que recorta, renuncia e “[...] opõe ao infinito da memória a finitude 
necessária da morte e a inscreve no âmago da narração.” (GAGNEBIN, 2011, p. 03). Pensando as caixas de memória como narrativas dos inúmeros sujeitos e grupos que vivenciaram a história do $\mathrm{CaVG}$, elas se colocam no mesmo tecer da rememoração onde o lembrar e o esquecer determinam a urdidura. No instante em que nos colocamos enquanto "guardiões" destas narrativas, somos levados inevitavelmente pelo mesmo movimento, construindo assim histórias a partir de histórias, memórias a partir de memórias e esquecimentos a partir de esquecimentos.

Dessa forma, as tantas indagações que nos surgiram, ao recebermos a caixa do professor, passam a ser percebidas como presenças que só foram possíveis pela ausência constatada, enquanto percebidas em sua ausência: a dona do chinelo perolado $n^{\circ} 34$, as caixas do " 1 " ao “27”. Ao mesmo tempo em que a morte do guia de Jonathan era necessidade latente ao não desaparecimento de seu avô. Neste caso, a necessidade de lembrar do protagonista fez sucumbir a necessidade de esquecimento de seu guia. Nós, por outro lado, desejamos continuar nossa busca profunda, mesmo que em passos desajeitados por entre as teias que as caixas tecem e rompem em movimento brusco, em profunda atenção às narrativas que podem constituir os sujeitos e grupos que ainda desejamos ver contados. Entretanto, fazendo isso com cuidado e atenção extrema aos processos rememorativos, que por entre a história e a literatura vão recortando, elegendo e eliminando na tenacidade das aberturas e dos fechamentos, do lembrar e do esquecer, do fio da vida e do fio da morte.

\section{Ainda cambaleantes, entre caixas, seguimos}

Buscando superar as dicotomias entre realidade e ficção, "histórias" e "história", fatos e mentiras, assumimos mais uma vez nosso trabalho na direção de uma comunidade de significação que apenas segue os que as narrativas que as caixas de memória nos gritam em (des)tecitura, apelo e exigência. Neste movimento, vivenciamos uma oficina de escrita que tinha como centro uma pequena caixa, repleta de memórias, esquecimentos, aberturas e fechamentos... Nosso desafio era apenas explorá-la e por breves instantes escrever algo que nos chegava... Ainda que não compreendêssemos esse "alguma coisa" esse "mesmo assim" (DIDIHUBERMAN, 2013). O papel que continha nossa escrita era o mesmo e circulava por todos os membros do grupo que participavam do encontro, que construíam a mesma narrativa, que se deu assim: 
RELACult - Revista Latino-Americana de Estudos em Cultura e Sociedade

Revista Latinoamericana de Estudios en Cultura y Sociedad | Latin American Journal of Studies in Culture and Society

V. 03, nº 02, mai-ago., 2017, p. 16-26 | relacult.claec.org e-ISSN 2016/Atual: 2525-7870 | e-ISSN 2015/2016: 2447-018X

A vontade para onde meus pés desejavam me levar Me coloca no lugar em que eu gostaria de ficar A escrita me constrange

E me é tão cara

Ela me antecipa

Não me faz sucumbir ao desânimo Permite que meus ataques sejam com as palavras

Me faz potente

Me faz transbordar

E derramar

Além do nível

Além do desejável

Do formatado!

A ânsia se faz em letras

A busca encontra alguns caminhos

O escrever me permite achar o que eu procuro

Traduz um pouco do que não consigo expressar

Me deixa em paz

Me faz ter a certeza de que viver não é em vão

As palavras me acolhem

Me sinto uma entre elas

Me refugio nos seus significados

Me abraço e me jogo buscando-as cada vez mais

E quando não as encontro

Busco um descanso, um repouso para um novo começar.

E não me sinto constrangida

Se é mais um palavrório

Me deleito com tantas a minha disposição.

Gosto de me encontrar com minhas escritas, gosto de as rever

Nelas minhas buscas encontram a doçura, a nostalgia, a revolta, o dilema, a contradição - a esperança, a utopia, o medo, a redenção.

Abro a caixa... encontro pedaços... pedaços de palavras... pedaços de tantos, pedaços de mim, pedaços de outros...

Quando abro alguma caixa me deparo com situações que na maioria das vezes parece pertencer a mim, sempre me remete algo que está ao meu redor.

Procuro por rastros, histórias de ontem, colocando-me como presente nesta. Uma viagem nas memórias de outros. Na procura, respostas que turbilham minha mente, mas mesmo

encontrando tais, novas questões sempre surgem nunca acalmando meu pensar.

Nas cartas, faltas, ausências, zelos, compromissos e paixões. Um tanto de nós e de outros.

Restos espalhados numa busca sem fim de sentir e dar sentido.

Márcia salta da caixa, salta em palavra arteira e atrevida. Ela foge, esconde-se, quer namorar. Quer fugir da aula, do inspetor, ela quer... O quê ela mais quer?

Memórias que voltam todo tempo, dos mais diversos modos, gera o exercício de nunca esquecer, existir uma lembrança independentemente de ser boa ou ruim, o exercício de nunca esquecer?

Objetos, imagens, escritos que afloram lembranças, memórias, sentimentos de pessoas, lugares, momentos passados e guardados que porventura "deixado" de lado nas correrias do hoje, mas nunca esquecidos.

"Escrevo estas mal notadas linhas, pedacinhos meus de saudades tua - ó inesquecível pedacinhos tão pequenos, mas tão imortais de nós." 
Lembranças do caos que fez existir e resistir...

“Emir, por favor, chama os alunos do quarto 6..." E agora são os alunos do quarto 6 que saltam, em palavra, de dentro da caixa... Emir deve chamá-los. Mas eles nem precisam deste chamado, eles saltam da caixa, eles nos revidam a palavra... suas vozes são gritaria que não cabe mais naquilo que passou... Esta gritaria é já- agora. Os olhos por um instante a um objeto, o poder de descrição de uma carta onde nos transporta e recria uma imagem ou acontecimento, acaba que nos insere mesmo que por um instante naquele fato narrado, é uma forma de se sentir abraçado, mesmo quando nos encontramos longe de tudo.

Ao abrir a caixa transporto-me para uma outra dimensão, que a cada leitura/visualização caminho por trilhas de memórias, estas que pedem socorro para serem relembradas. Vozes em gritaria, vista apenas por pessoas sensíveis. "Serenamente dou o primeiro passo" - "Eu me conformo com tudo neste mundo" - Despeçome com saudade e espero que permitas receber meu abraço, meu pedaço de papel, meu registro, um pouco de tudo que ainda persiste em resistir." Agora eles saltam em imagem, olho pela porta e os vejo em tom sépia, no meio do campo, em seus trajes que os fazem parecer pequenos refugiados, pequenos apenados. Eles estão no campo trabalhando. Eles param e me olham. Agora sou eu própria a lente da câmera e eles me revidam o olhar, não mais pela palavra, mas por seu rosto que me diz algo que ainda não

aprendi a ler. Mas sigo entre palavras-caixa e rostos-caixa.

A importância do guardar para recordar, não apenas pensando no esquecimento, mas sim no poder que o objeto tem de nos transportar e reviver algum momento, com detalhes únicos. $O$ ato de esperar a carta, a ansiedade de trocar informações e ao mesmo tempo a satisfação de receber. As trocas que nos mantem vivo e o arquivo que não queremos esquecer. E assim entre um chimarrão e uma escrita, reflito no que escrevo e por que escrevi, algumas respostas não tenho e nunca terei, mas mesmo assim continuo a olhar o ontem, sem deixar de pensar no hoje, momentos paralelos de uma existência.

\section{Considerações finais}

Marcio Seligmann-Silva $(2003 ; 2005 ; 2006)$ é um dos principais autores que contemporaneamente tem defendido a imprescindível aproximação entre a história e a literatura, principalmente, a partir da Literatura de Testemunho. Para o autor, tal literatura tem exigido que muitos teóricos revejam a relação entre ficção e realidade. "O conceito de testemunho desloca o 'real' para uma área de sombra: testemunha-se, via de regra, algo de excepcional e que exige um relato. Esse relato não é só jornalístico, reportagem, mas é marcado também pelo elemento singular do 'real.' (SELIGMANN-SILVA, 2003, p. 47). Na mesma perspectiva, o autor defenderá um conceito aberto da noção de testemunho, onde não só quem viveu algo pode testemunhá-lo, mas que a literatura sempre teve e terá um teor testemunhal. Ao mesmo tempo, o real aqui concebido, é algo que nos exige repensar nossa visão da história, ou, mais precisamente, do fato histórico. O real presente na literatura do testemunho é pensado sempre como trauma, e a narrativa será fruto de um indizível que a desencadeou.

Nesse contexto, a história é pensada como trauma, como ferida aberta, ou, em termos benjaminianos, como barbárie ainda não redimida, onde os vencedores ainda não pararam de 
vencer e ainda cortejam sob os corpos dos mortos e dos vivos (BENJAMIN, 2012). A experiência traumática para Freud (1996) é aquela que não pode ser totalmente assimilada enquanto ocorre. Por isso, o testemunho de uma história traumática sempre irá se colocar entre a narração daquilo que foi vivido e dos esquecimentos ainda necessários ao prosseguimento da vida. Lembrar aqui não pode se dar sem o esquecer. Diante disso, Seligmann-Silva (2003, p. 49,50) adverte: “[...] fica mais claro que nunca que a questão não está na existência ou não da 'realidade', mas na nossa capacidade de percebê-la e de simbolizá-la”. O autor reafirmará que a memória só existe em relação com o esquecimento, um alimenta o outro. Dessa forma, a verdade é concebida em termos de uma coerência simbólica de preservação da vida e da luta por sua libertação e, para isso, ela muitas vezes deverá trilhar entre o lembrar e o esquecer, entre a história e a literatura, entre o real e o ficcional.

A abordagem a qual se ancora a literatura de testemunho, como também do referencial que vimos aqui nos ancorando (DIDI-HUBERMAN, 2007; 2013; GAGNEBIN, 2011; SELIGMANN-SILVA, 2003 ; BENJAMIN, 2012), é aquela que se aproxima do campo estético, em busca da "voz correta", aquela capaz de desconstruir o contínuo da historiografia tradicional, incorporando uma leitura estética do passado, "desmusealizando" o que se passou e mantendo o passado ativo no presente (SELIGMANN-SILVA, 2003).

Partindo da imagem das caixas de memória, foi este o mesmo percurso que procuramos demonstrar neste texto, uma perspectiva de trabalho com acervos que assume o cambaleio de seus passos em um inevitável processo de aberturas e fechamentos. Ao tatearmos por entre as pilhas de caixa, não buscamos uma indexação do passado, mas uma possível apresentação de seus fragmentos, marcas e cicatrizes.

\section{Referências}

BENJAMIN Walter. Sobre o conceito de história. In: BENJAMIN, Walter. O anjo da história. Belo Horizonte: Autêntica, 2012. P.08-20.

DIDI-HUBERMAN, Georges. La imagen mariposa. Barcelona: Mudito \& Co, 2007.

DIDI-HUBERMAN, Georges. Diante da imagem. São Paulo: Ed 34, 2013.

FREUD, Sigmund. Além do princípio de prazer. Rio de Janeiro: Imago, 1996.

GAGNEBIN, Jeanne-Marie. História e narração em Walter Benjamin. São Paulo: Perspectivas, 2011.

RIBEIRO, M. Uma vida iluminada: trajetórias sociais de pessoas e objetos na reconstrução de memórias pós holocausto. IN: Proa-Revista de Antropologia e Arte [on-line]. Ano 02, 
RELACult - Revista Latino-Americana de Estudos em Cultura e Sociedade

Revista Latinoamericana de Estudios en Cultura y Sociedad | Latin American Journal of Studies in Culture and Society V. 03, no 02, mai-ago., 2017, p. 16-26| relacult.claec.org e-ISSN 2016/Atual: 2525-7870 | e-ISSN 2015/2016: 2447-018X

vol.01, n. 02, nov. 2010. Disponível em:

<http://www.ifch.unicamp.br/proa/ResenhasII/magda.html> Acesso em: 31 jul. 2016.

SELIGMANN-SILVA, Márcio. História, memória e literatura. O testemunho na era das catástrofe. Campinas: Unicamp, 2003. 